\title{
ARISTOTLE ON \\ ESSENCE AND HABITAT
}

\author{
JESSICA GELBER
}

\section{Introduction}

AristotLE was aware that organisms have parts and organs that are well suited to exercising their distinctive vital capacities, such as their capacities for locomotion, reproduction, self-maintenance, and perception. The presence of those well-suited parts and organs is, Aristotle thinks, no accident. These parts are present for the sake of those vital activities and functions they are used to perform:

Since every instrument is for the sake of something, and each of the parts of the body is for the sake of something, and what they are for the sake of is a certain action, it is apparent that the entire body too has been constituted for the sake of a certain complete action. For sawing is not for the sake of the saw but the saw for sawing; for sawing is a certain use. So the body too is in a way for the sake of the soul, and the parts are for the sake of the functions in relation to which each of them has naturally developed. ( $P A$ I. $5,645^{\mathrm{b}} \mathrm{I} 4-20$, trans. Lennox)

Aristotle was also aware that organisms have, by and large, parts and organs that are well suited to life in a certain kind of habitat. ${ }^{\mathrm{I}}$ (By 'habitat' I mean an ecological environment characterized both

\section{(C) Jessica Gelber 2015}

I am grateful to the organizers and participants of the 36th Annual Workshop in Ancient Philosophy, particularly my commentator, Eve Rabinoff, as well as to Anna Marmodoro and members of her seminar in Oxford, for their extremely helpful suggestions for improvement. I also benefited greatly from discussions with Michael Caie, Kim Frost, Devin Henry, Joe Karbowski, Sean Kelsey, Jim Lennox, Hille Paakkunainen, Kara Richardson, and Joel Yurdin. Brad Inwood also deserves many thanks for his editorial assistance and advice. I would especially like to express my gratitude to Kathleen C. Cook.

${ }^{1}$ I am oversimplifying matters here in speaking as though an organism has only a single habitat, since Aristotle distinguishes several respects in which something might be, for example, a water-, marsh-, or land-dweller. As Aristotle discusses in $H A 7$ (8). 2, an animal might be a water-dweller with respect to feeding, but a landdweller with respect to cooling, for instance. This becomes relevant for Aristotle when he is discussing (e.g. in $P A$ 4. I3) kinds that 'tend to both sides'-ones that have one habitat for certain vital activities and a different habitat for others. My 
by abiotic features such as moisture, light, and temperature, and by biotic ones, such as the availability of certain kinds of plants and animals as food or shelter, or the presence of predators or rivals.) His biological works contain numerous references to the co-ordination between the parts or organs that a kind of organism uses to exercise its vital capacities, and the conditions in the habitat in which it does so. For instance, he notes that the hard lining of the camel's mouth allows it to consume the type of vegetation-viz. thorny cactus plants - that grow in the deserts where the camel lives $\left(P A_{3}\right.$. I4, $\left.674^{\mathrm{a}} 22^{-\mathrm{b}} 5\right)$, that the flat beak of certain marsh birds is useful for digging up roots in the mud ( $P A_{4}$. I $2,693^{\mathrm{a}}{ }^{\mathrm{I}} \mathrm{I} \mathrm{ff}$.), and that birds that live near water can swim more easily because of the webbing between their toes ( $P A_{4}$. I2, $694^{\mathrm{b}} 6 \mathrm{ff}$.). Reflection on these facts quite naturally leads us to ask what accounts for the fit between these organisms and their habitats. I will call such a question a 'question of fit'. But Aristotle, despite his awareness of those same facts, never asks any such question. ${ }^{2}$

discussion of habitat is consistent with this complication, and so for the most part I will overlook it. (For discussions of these kinds, which are sometimes called (perhaps misleadingly) 'dualizers', see D. M. Balme, 'Aristotle's Use of Division and Differentiae', in A. Gotthelf and J. G. Lennox (eds.), Philosophical Issues in Aristotle's Biology [Issues] (Cambridge, I987), 69-89; A. Gotthelf, 'First Principles in Aristotle's Parts of Animals' ['First Principles'], in Gotthelf and Lennox (eds.), Issues, I 67-98, repr. in A. Gotthelf, Teleology, First Principles, and Scientific Method in Aristotle's Biology [Teleology] (Oxford, 2012), I 53-85; J. G. Lennox, 'Divide and Explain: The Posterior Analytics in Practice', in Gotthelf and Lennox (eds.), Issues, 90-I I 9, repr. in J. G. Lennox, Aristotle's Philosophy of Biology: Studies in the Origins of Life Science [Biology] (Cambridge, 200I), 7-38; J. G. Lennox, 'Bios and Explanatory Unity in Aristotle's Biology' ['Bios'], in D. Charles (ed.), Definition in Greek

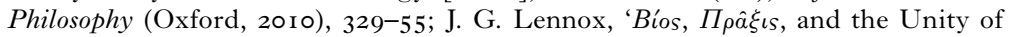

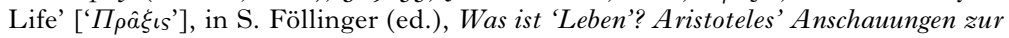
Entstehung und Funktionsweise von Leben. Akten der Tagung vom 23.-26. August 2006 in Bamberg (Stuttgart, 2010), 239-59.)

${ }^{2}$ Asking what accounts for the fit between organisms and their habitats is not the same as asking why organisms are found in habitats to which they are well suited. Questions of fit are questions of the form 'Why are fish so well suited to life in water?', rather than 'Why are fish found in water?'. Call questions of this latter sort 'distribution questions'. One way to see that these questions are distinct is by noting that one could answer all of the questions of fit and yet still not have an answer to distribution questions: we could understand why there is a fit between fish and water, but still wonder why it is that fish are actually living in water, rather than eking out their existence in some less than ideal circumstances. I suspect that the tendency to conflate these two questions is in part explained by the fact that we usually answer both questions by appeals to an organism's evolutionary history. Although Aristotle does not ask either of these sorts of question, my focus here is only on why he does not raise questions of fit. 
It is unlikely that Aristotle thinks this 'fit' (as I am calling it) between organisms and their habitats is merely a lucky coincidence. In Physics 2. 8 he rejects the idea that regularly occurring, beneficial arrangements of parts within the body-such as our teeth being arranged suitably for biting and grinding food-could be merely due to chance. So, it is natural to expect that Aristotle would consider the beneficial co-ordination between organisms and their habitats to be equally non-accidental. The co-ordination between the parts of the body is not sufficient to explain the survival and flourishing of a kind; if the kind does not have a co-operative habitat, having teeth that are suitable for biting and grinding, for example, would be of little use.

Darwinians and Creationists have ready explanations. The former can tell an evolutionary story about how organisms evolved to be the way they are; the latter can appeal to an Intelligent Designer's grand plans for producing such a good fit. On the assumption that Aristotle is neither a Darwinian nor a Creationist, however, these answers are not available to him.

In what follows I will first consider two possible strategies for reconstructing Aristotle's answer to questions of fit. The first is going to appeal to a global or cosmic version of natural teleology. The second will give the conditions in various habitats an efficientcausal role in shaping the character of the organisms living in them. Neither of these approaches, as I will argue, provides an attractive answer.

What I will propose instead is a way of understanding Aristotle's views about the essences of living substances, i.e. the 'what-it-isto-be' for living creatures, that explains why he would not ask any questions of fit. In short, my proposal will be that habitat is partially constitutive of the vital capacities that comprise a kind's essence. Consequently, whereas we might think that questions of fit are urgent, for Aristotle those questions would not arise. For, just as asking why swimming takes place in water evinces some confusion about what swimming is, Aristotle would think that asking a question of fit betrays a misunderstanding about what the objects of natural science are. Swimming is a kind of movement that takes place-essentially-in water. So, too, all of an organism's psychic capacities are ones that take place-essentially-in certain types of environment. The various activities that comprise the life of a kind of organism cannot even be specified without referring 
to the habitats in which those activities are performed. The way of thinking about the essences of living kinds that I will attribute to Aristotle yields a richer and more nuanced view about natural substances than the abstract and programmatic discussions in the Physics suggest. ${ }^{3}$

\section{Global teleology}

One approach to answering questions of fit is to read Aristotle as endorsing a 'cosmic' or 'global' version of natural teleology in the way advocated by David Sedley. ${ }^{4}$ On Sedley's view, the beneficial coordination between organisms and their habitats is to be explained teleologically. The conditions that make life possible-especially human life-are such as they are for the sake of doing just that:

Clearly the world as a whole is structured in many ways that are regularly beneficial to life, including the availability of natural resources, and the eternally recurrent intertransformation of the four simple bodies that underlies the weather cycle, this latter dependent in turn on the daily and annual cycles of the sun. If Aristotle conceded that these advantageous cosmic structures require no teleological explanation, he would be playing into the hands of his opponents by implying that advantageous structures in individual organisms might equally well be understood as nonpurposive. ${ }^{5}$

Although Sedley's interpretation is subtler and more complicated than I can do justice to here, ${ }^{6}$ I take the crux of it to be the following. In Sedley's view, Aristotle holds that goal directedness in

3 It will simply be false, pace $\mathrm{S}$. Waterlow, to say that Aristotle thinks the conditions in a certain habitat merely 'provide the stage' (S. Waterlow, Nature, Change, and Agency in Aristotle's Physics [Nature] (Oxford, I982), 38) or 'arena' (ibid. 33) in which an individual substance's activities are carried out, or that Aristotle does not consider positive descriptions of those conditions important to understanding the natures of living organisms (ibid. 33).

4 See D. Sedley, 'Is Aristotle's Teleology Anthropocentric?' ['Anthropocentric'], Phronesis, 36 (I991), I 79-96; 'Metaphysics A', in D. Charles and M. Frede (eds.), Aristotle's Metaphysics A: Proceedings of the Fourteenth Symposium Aristotelicum (Oxford, 2000), 327-50; Creationism and its Critics in Antiquity [Creationism] (Berkeley, 2007); and 'Teleology, Aristotelian and Platonic', in J. G. Lennox and R. Bolton (eds.), Being, Nature, and Life in Aristotle: Essays in Honor of Allan Gotthelf (Cambridge, 2010), 5-29.

5 Sedley, Creationism, 196.

${ }^{6}$ I am glossing over, in particular, the anthropocentric aspect of Sedley's interpretation: 'Nature is anthropocentric to the extent that man is the ultimate beneficiary, while god remains the ultimate object of aspiration, that which all lesser beings strive to imitate' (Sedley, 'Anthropocentric', I 80). On Sedley's interpretation, all natural 
nature extends beyond the development and characteristic behaviours of individual substances and to the cosmos considered as a whole. Not only the reproduction and maintenance of individual living beings, but also the motions of celestial bodies, the cycles of elemental transformation, and sublunary weather patterns are goaldirected processes.

The shared goal of all these natural phenomena, furthermore, is the emulation of the Unmoved Mover's perfect activity, which each thing does in its own way. A living organism emulates divine actuality by reproducing another like itself. ${ }^{7}$ The elements do this by continual, cyclical transformation into each other. ${ }^{8}$

It is important to note that on Sedley's interpretation, moreover, it is not merely the shared striving to emulate god's perfect actuality that ensures and so explains that good order will obtain among all the parts of the cosmos. ${ }^{9}$ After all, the fact that the Unmoved Mover serves as the 'metaphysical magnet' ${ }^{\prime}$ drawing all things towards it is surely compatible with a lack of co-ordination. In order for that shared goal to be providing a genuine explanation, there needs to be some connection between the single, common aim and the coordination and fit between natural entities. Without such a connection, there is nothing that guarantees that order will emerge. Sedley forges a link, on Aristotle's behalf, between each natural entity's aim to emulate god's perfect actuality and their mutual co-ordination (including organisms' fit with their habitats) by positing a 'cosmic

phenomena ultimately aim to emulate god's perfection, but natural phenomena are for the sake of humans-the highest species-in the sense that they benefit humans. (For the distinction between aim and beneficiary see $D A 2.4,4{ }^{\mathrm{I}} 5^{\mathrm{a}} 23^{-\mathrm{b}} 7,4^{\mathrm{I}} 5^{\mathrm{b}} \mathrm{I}_{5}-2 \mathrm{I}$; Phys. 2. 2, 194 ${ }^{\mathrm{a}} 33^{-6}$; Metaph. $\Lambda$ 7, $1072^{\mathrm{b}} \mathrm{I}-4$.)

7 Cf. $G A$ 2. I, $73^{\mathrm{I}}{ }^{\mathrm{b}} 3 \mathrm{I}-732^{\mathrm{a}} \mathrm{I} ; D A$ 2. $4,4 \mathrm{I} 5^{\mathrm{a}} 25 \mathrm{ff}$.

${ }^{8} G C$ 2. го, $337^{\mathrm{a}}$ I ff.; Meteor. I. 9, $346^{\mathrm{b}} 35 \mathrm{ff}$.

9 The idea that a shared aim gives rise to co-ordination is expressed by I. Bodnár, who writes that 'Aristotle submits that there is a joint-arrangement, that every single entity is jointly arranged in relation to all the others and that this joint-arrangement arises due to the fact that each of these entities is related to the single entity at the pinnacle of this arrangement' (I. Bodnár, 'Teleology across Natures' ['Teleology'], Rhizai, 2 (2005), 9-29 at 22). Similarly, M. Leunissen claims that in Aristotle's view, the 'goodness, order, and joint arrangement of the cosmos as a whole emerge from the goal-directed actions of the individual parts of the cosmos towards the same end, the Unmoved Mover' (M. Leunissen, Explanation and Teleology in Aristotle's Science of Nature [Explanation] (Cambridge, 2010), 47).

10 This phrase is borrowed from C. Kahn, 'The Place of the Prime Mover in Aristotle's Teleology', in A. Gotthelf (ed.), Aristotle on Nature and Living Things [Nature] (Pittsburgh, I985), I 83-205 at I 84 . 
nature', over and above the individual natures. On Sedley's interpretation, every part of the cosmos strives to emulate god's perfect activity. This striving by any given part of nature, however, does not take place in a vacuum, but within a larger system. The larger system of which each is a part constrains or determines what the best possible emulation of god's perfect activity consists in, just as an organism's entire body constrains what optimal functioning of any particular part of it will involve. So, for instance, the lung is an organ for cooling. But how that cooling function is best carried out is in large part dependent upon what the other body parts are like. Optimal cooling is not necessarily the highest degree of cooling; what is optimal depends on factors such as the degree of heat in an organism's heart. So too, what the best possible emulation of god's perfection can be for any part of nature is determined by its place in the universe as a whole.

Sedley's proposal, then, is that the whole universe is analogous to an individual organism. Like an individual organism, the universe has a nature, over and above the individual natures. And this 'cosmic nature' co-ordinates its parts such that each part is able to emulate god's perfect activity in the best possible way:

Just as the nature of an animal can be invoked to explain why it has the parts that it does, including some that are at the service of others, so too the nature of the world, including the sublunary realm's complex goal-directed structure with man at its apex, can be invoked to explain why it contains the species, weather-systems, and other amenities that it does. ${ }^{\text {II }}$

What this interpretation makes room for is an explanation of the coordination between organisms and their habitats. Given that each part of nature is striving to imitate god's perfection, and that what such imitating involves depends on its place in the cosmos, it will turn out that the co-ordination between organisms and their habitats is simply a permanent feature of the well-ordered world, just

II Sedley, Creationism, 203. Sedley's evidence for his interpretation is primarily the analogy drawn in Metaph. $\Lambda$ I0, $1075^{\mathrm{a}} \mathrm{I} \mathrm{I}-25$, between the universe and armies (and households), where the 'joint-arrangement' of the components appears to be explained by their being 'jointly arranged in relation to one thing'. Although Aristotle does not say as much explicitly, we can imagine that the soldiers in an army are arranged in relation to each other-there is beneficial co-ordination among their actions-in virtue of their sharing the same goal, perhaps obeying the orders of the general. For discussions of Sedley's treatment of this passage see Bodnár, 'Teleology', I 7-2I, and R. Wardy, 'Aristotelian Rainfall or the Lore of Averages' ['Rainfall'], Phronesis, 38 ( I 993), I 8-30 at 23-6. 
as the 'teleological functioning of the parts of the body constitutes a permanent symbiotic interrelation'. ${ }^{12}$

An interpretation of Aristotle's teleology such as Sedley's may provide an answer, for Aristotle, to questions of fit. But there are reasons to wonder whether this is really Aristotle's view. There is, as Sedley's critics have pointed out, at least a prima facie tension between the idea that there is a cosmic nature, analogous to the natures of individual living beings, and Aristotle's metaphysics of substance. ${ }^{13}$ Aristotle says in the Physics that only substances have natures $\left(192^{\mathrm{b}} 32-3\right)$. So, if the cosmos is to have a nature, it must be a substance, which seems to imply that the inhabitants of the cosmos are parts of that substance. But Aristotle also appears to think that parts of substances are not substances, or at least are only substances in potential (Metaph. $Z \mathrm{I}_{6} 6, \mathrm{I}_{4} \mathrm{O}^{\mathrm{b}} 5 \mathrm{ff}$.). If so, this threatens the status of living things-given that they are parts of the cosmosas paradigmatic substances (cf. Metaph. $Z$ 7, $1032^{\mathrm{a}}{ }^{\mathrm{a}} 9 ; Z 8,1034^{\mathrm{a}} 4$; $\left.H_{3}, \mathrm{I}_{0} 3^{\mathrm{b}} 2 \mathrm{I}-3\right)$.

Sedley's interpretation has also been criticized for its rejection of what has been called Aristotle's 'teleological axiom' that 'nature does what is best among the possibilities for the animal's own being'. ${ }^{14}$ Aristotle's reference to the final cause in Physics 2. 7, $198^{\mathrm{b}} 8-9$, as being what is 'better thus, not simply, but in relation to the being of each thing', is taken by many scholars as explicitly restricting the scope of goal-directed natural processes to those that benefit the same natural entity as that which undergoes the process. ${ }^{15}$ Although there are ways of reading Aristotle's claim in Physics 2. 7 that are amenable to Sedley's view, ${ }^{16}$ Aristotle's practices in his biological works-where there are very few passages that do not clearly con-

12 Sedley, 'Anthropocentric', I 87.

I3 See Wardy, 'Rainfall', and Bodnár, 'Teleology', for objections to the existence of a cosmic nature in Aristotle's ontology.

${ }^{14}$ J. G. Lennox, Aristotle: On the Parts of Animals $I-I V$. Translated with an Introduction and Commentary [Parts] (Oxford, 200I), 34I.

15 See L. Judson, 'Aristotelian Teleology' ['Aristotelian'], Oxford Studies in Ancient Philosophy, 29 (2005), 34I-66 at 359-62, and Lennox, Parts, 34I. D. M. Balme claims that Aristotle's statement in Physics 2. 7 'cannot be reconciled' with global teleology (Aristotle: De partibus animalium $I$ and De generatione animalium $I$ (with Passages from II. I-3). Translated with Notes, with a Report on Recent Work and an Additional Bibliography [De partibus] (Oxford, 1992), 96). Aristotle makes similar remarks at $I A 2,704^{\mathrm{b}} \mathrm{I}_{5}{ }^{-1} 7$, and $G A 5.8,788^{\mathrm{b}} 20-5$.

${ }^{16}$ Sedley suggests that the contrast intended between better 'simply' and better 'in relation to each being' is that between being better relative to some being or other and being better 'absolutely', and takes Aristotle to be denying Plato's view in the 
form to that 'axiom'-is thought to tell against such an alternative reading. ${ }^{17}$

I will add to the list of worries the fact that Aristotle does not seem to offer any argument for the existence of a cosmic nature. As I understand it, Aristotle's argument for positing goal-directed natures that co-ordinate the parts of individual organisms relies heavily on observations of the regularity with which these beneficial structures are produced. ${ }^{18}$ In an eternal, ungenerated universe there is no analogous reproductive regularity to be observed. Consequently, the same kind of argument as he gives for goal-directed individual natures cannot be applied in the case of a cosmic nature. It might be Aristotle's view that the whole universe has a nature like the natures of individual organisms, and that this cosmic nature is responsible for the beneficial distribution of organisms in suitable habitats. If that is his view, however, it is one for which he does not appear to give an argument. And this is surprising, given that he clearly sees the need to argue against those who deny that there are individual, goal-directed natures.

These criticisms of Sedley's interpretation are not decisive. However, in the light of the fact that his interpretation requires quite

Timaeus that features of the world can be intrinsically good, and 'not because they do anyone any good' ('Anthropocentric', 190).

${ }^{17}$ As M. Leunissen interprets Aristotle, this teleological axiom applies only to cases of what she calls 'primary teleology', but not to what she calls 'secondary teleology'. On her interpretation, cases of secondary teleology are cases of 'any agentinternal or external-making use of things available by nature for its own good, such as living beings using each other as food' (Explanation, 25). This distinction might provide a way to read various comments (such as that at $P A{ }_{4} .1_{3}, 696^{\mathrm{b}} 24 \mathrm{ff}$., where Aristotle claims that the placement of the dolphin's mouth is for the sake of preserving other animals) in a way that does not conflict with the teleological axiom, since one can maintain that these are cases of secondary teleology, and the axiom applies only to primary teleology. Unfortunately, however, I do not think appealing to secondary teleology will provide a satisfying answer to questions of fit. For the answer would be that the habitat is for the sake of the kind-though only in the secondary way-in that 'the formal nature of one natural being appropriates the potentials available in another natural being in order to use it for its own benefit' (ibid. 48). That is, the sense in which the habitat is for the sake of the organisms is that the habitat gets used by or is useful for organisms. However, since questions of fit are questions about why a habitat is useful for an organism, such an answer would seem merely to restate the explanandum.

${ }^{18}$ For a discussion of the relevance of regular reproduction from seed in Aristotle's argument for natural teleology see A. Code, 'The Priority of Final Causes over Efficient Causes in Aristotle's $P A$ ', in W. Kullmann and S. Föllinger (eds.), Aristotelische Biologie: Intentionen, Methoden, Ergebnisse [Biologie] (Stuttgart, I 997), I $27-43$. 
controversial assumptions, a proposal for how Aristotle would answer questions of fit that presupposes it is not appealing. ${ }^{19}$

\section{Adaptation}

Sometimes Aristotle speaks about an organism's habitat in a way that strongly suggests a causal and explanatory account running from facts about a habitat to facts about an organism's parts and features. In $P A$ 4. I2, for instance, he says that 'Some birds are long-legged. The cause [aition] of this is their marsh-dweller way of life' $\left(694^{\mathrm{b}} \mathrm{I} 2\right)$. Comments such as this indicate that Aristotle thinks there is a causal account proceeding from facts about the habitat to facts about the body parts and features of the living organisms in it.

As is well known, Aristotle thinks there are four ways of being a cause, so there is a question about which he means to be referring to here. If one were tempted to read this as signalling an efficientcausal account, as opposed to a formal- or final-causal one, ${ }^{20}$ further support might be garnered from the fact that there are other passages in which an efficient-causal role is given to environmental conditions such as climate. For example, $G A 5 \cdot 3$ contains a description of the way variations in hair thickness result from differences in the temperature and humidity of a given region. The reason organisms have hair at all is protection, but how thick or thin, straight or curly the hair is depends on factors such as the amount of heat and fluidity present while it is forming. So, for example, Scythians and Thracians have straight hair, in part because the surrounding air is moist, whereas those who live in hot and dry regions such as Ethiopia have curly hair $\left(782^{\mathrm{b}} 33^{-78} 3^{\mathrm{a}} \mathrm{I}\right)$. And in $G A 4.2$ facts about climate and a region's water are said to play a role in determining the sex of an embryo ( $\left.767^{\mathrm{a}} 28-35\right)$. In addition, Mariska Leunissen has recently argued that Aristotle holds a version of what she calls 'environmental determinism' about the development of character. ${ }^{21}$ Leunissen argues that in Aristotle's view, an organism's ethos or natural character-its being timid, mild, courageous, gentle, intelli-

19 The interpretation that I will be arguing for is, in fact, compatible with Sedley's, but it does not require it.

${ }_{20}$ I will argue that this should be read as a teleological explanation.

${ }^{21}$ M. Leunissen, 'Aristotle on Natural Character and its Implications for Moral Development' ['Character'], Fournal of the History of Philosophy, 50 (201 2), 507-30 at 509 . 
gent, or stupid-is causally determined by 'external environmental factors'. ${ }^{22}$

So, in certain cases, Aristotle may hold that an organism's features are efficient-causal effects of conditions in its environment. Those cases, however, are importantly different from the ones I am concerned with here. In each of those examples just mentioned, there is a material-efficient causal account that goes from environmental factors, by way of the organism's elemental composition or bodily 'blend' (krasis), to some characteristic or feature. Here the environment is thought to influence the outcome via its causal influence on the quality of the material constitution of an organism. Questions of fit, however, are about the co-ordination between habitat and the parts that are suited to performing their functions in those habitats, and it is doubtful that a similar efficientcausal account can be given for those.

There are at least three reasons for this doubt. First, Aristotle gives no indication that he thinks that a causal story going from the effects of climate on the organism's bodily blend to the organism's part or feature could be told about the long legs of the marshdweller bird. It is equally unclear that he thinks that this could be the case for the flat beaks of the swamp-dweller, vegetarian birds ( $P A$ 4. I 2, 693 ${ }^{\mathrm{a}}$ I I ff.) and the webbed feet of the aquatic birds ( $P A$ 4. $12,694^{\mathrm{b}} 6 \mathrm{ff}$.), or the hard roof of the mouth and multiple stomachs of the thorny-food-eating ${ }^{23} \operatorname{camel}\left(P A_{3} \cdot \mathrm{I}_{4}, 674^{\mathrm{a}} 22^{\mathrm{b}}{ }^{\mathrm{b}}\right)$. Unlike, for example, hair thickness, there is no attempt on Aristotle's part to explain how temperature and humidity give rise to variations in the shapes and structures of these sorts of parts or organs. At least in the case of hair thickness, Aristotle appeals to rates of evaporation and amounts and qualities of moisture being evaporated. Second, even if there were some way to tell such a story, it would need to include the environment's efficient-casual effect on the organisms' activities and functions. For Aristotle thinks that the character of the function that a part is used to perform is explanatorily prior to

\footnotetext{
${ }^{22}$ Leunissen argues that an organism's natural character depends on its elemental 'blend', which blend is in turn 'changeable by efficient-causal changes due to aging and disease, diet, and external environmental factors' ('Character', 509). Leunissen cites Pol. 7. 7, $1327^{\mathrm{b}} \mathrm{1} 8-38$, as evidence that Aristotle thinks the natural character traits of an individual human 'depend on the climate where it lives' (ibid.).

${ }^{23}$ See Lennox, 'Bios', 338-9 n. I4, for a discussion of the tight connection between the 'material constitution of the food source' and an organism's habitat. I am accepting Lennox's suggestion that references to nourishment be read as emphasizing the habitat rather than the food.
} 
the character of the part. Third, this would not explain why an organism's parts and activities should turn out to be suitable in those conditions. That is, the fact that some part of an animal is a result of certain efficient-causal influences in no way guarantees that the part will be beneficial to the animal in the conditions that exert this causal influence.

Is there some other way-that is, other than environmental influence on the bodily blend-in which organisms' features can be considered as effects of the conditions in their environments? Some scholars claim that the sorts of examples just cited are instances of adaptation by an organism to its environment. ${ }^{24}$ If we take 'adapt' simply to mean 'change in response to the environment', it seems reasonable that Aristotle would think there are plenty of ways that an organism can do this. There are, for instance, extended discussions of the ways different kinds of organisms respond to seasonal changes by hibernating $(H A 7(8)$. I4-I 7$)$ and migrating $(H A$ 7 (8). I $2-13)$.

There is, however, a limit to the kinds of change an individual organism's nature could undergo in response to its environment. And changes to an organism's body parts that are needed to perform certain functions seem to lie well beyond that point. The problem with this idea is not merely the fact that it seems implausible to think that an organism could grow longer legs in response to finding itself in a marsh in the way it might go into hiding in response to a drop in temperature, or that a bird could develop webbing between its toes in response to living in water, just as it might fly to warmer regions when winter arrives. ${ }^{25}$ The problem with this as an interpretation of Aristotle is that changes such as those in the size, shape, or position

\footnotetext{
${ }^{24}$ Judson, 'Aristotelian', 355 n. 46; Lennox, Parts, 33I; Leunissen, Explanation, 42 .

${ }^{25}$ Lamarck, after all, thought this was the case: 'We find in the same way that the bird of the water-side which does not like swimming and yet is in need of going to the water's edge to secure its prey, is continually liable to sink in the mud. Now this bird tries to act in such a way that its body should not be immersed in the liquid, and hence makes its best efforts to stretch and lengthen its legs ... The bird which is drawn to the water by its need of finding there the prey on which it lives, separates the digits of its feet in trying to strike the water and move about on the surface. The skin which unites these digits at their base acquires the habit of being stretched by these continually repeated separations of the digits; thus in the course of time there are formed large webs which unite the digits of ducks, geese, etc., as we actually find them. In the same way efforts to swim, that is to push against the water so as to move about in it, have stretched the membranes between the digits of frogs, sea-tortoises, the otter, beaver, etc.' (J. B. Lamarck, Zoological Philosophy: An Exposition with
} 
of body parts would require changes in the functions and activities those parts are needed to perform: the functions and activities have, in Aristotle's view, causal and explanatory priority over the parts. And, I submit, an organism cannot modify its essential vital activities within a single lifespan. ${ }^{26}$

The idea that there can be adaptations of essential activities would be reasonable, perhaps, given the assumption that species evolve over time. If species evolve-if some species go out of existence and new species come to be-there is nothing obviously incoherent about there being modifications to essential activities and functions. Yet although there may be nothing in Aristotle's theory that is inconsistent with evolution, there is no evidence that Aristotle does think species evolve. The consensus view, on the contrary, is that Aristotle believes in the permanence and fixity of the species-that the world has always contained the kinds of organisms it does-and that this would be the most reasonable position to take, given the lack of palaeontological evidence in his day. ${ }^{27}$ In order to accept that Aristotle's answer to questions of fit is that 'the kind adapted to its environment', we must then be willing to endorse the view that, according to Aristotle, species evolve. However, since the latter view is unattractive, so consequently is the former.

\section{Habitat and essence}

So far, I have considered two possible, though problematic, answers to questions of fit. The first answer requires the assumption that Aristotle's ontology includes an overall, cosmic nature. The second answer is hard to square with Aristotle's belief that functions are prior to parts, as well as his views about the fixity of kinds.

regard to the Natural History of Animals, translated, with an introduction by Hugh Elliot (London, I914), I I9).

${ }^{26}$ This does not mean that an organism will not behave differently in different circumstances. However, not all differences in behaviour are manifestations of differences in vital capacities. I discuss this further below, in sect. 6 .

${ }_{27}$ See e.g. J. Cooper, 'Aristotle on Natural Teleology', in M. Nussbaum and M. Schofield (eds.), Language and Logos: Studies in Ancient Greek Philosophy Presented to G. E. L. Owen (Cambridge, I982), I97-222 at $202 \mathrm{ff}$.; J. G. Lennox, 'Kinds, Forms of Kinds, and the More and the Less in Aristotle's Biology', in Gotthelf and Lennox (eds.), Issues, 339-59 at 359, repr. in Lennox, Biology, I 60-8 I at I 78; Balme, De partibus, 97-8. 
Here I want to consider a different, more promising strategy, one that shows why questions of fit are, in effect, the wrong sort of questions to expect Aristotle to be asking, given his conception of living substances. This strategy, in short, is to reconceive of the relation between habitats and organisms. In my view, Aristotle considers habitat to be partially constitutive of the capacities that comprise a kind's essence, and not merely an external or enabling condition under which an organism can exercise its essential capacities. An attractive feature of this interpretation is that it explains why Aristotle would not raise any questions of fit: there is no need to ask why an animal is well suited to the habitat in which it lives if its habitat is already included in what it is to be an animal of that kind.

The idea that habitat is part of an organism's essence, and that habitat accordingly plays an explanatory role in scientific investigations about the kind, is not original with me. Long ago, for example, Allan Gotthelf noted that the elephant's being a marsh-dweller is one of the 'multiple essential features' that Aristotle appeals to in his complicated explanation of the elephant's distinctive trunk..$^{28}$ And in recent papers Jim Lennox has pointed out that a kind's 'way of life' or bios—of which habitat is one important aspect—'is occasionally identified as a fundamental feature of its being; and particular divisions of ways of life as general differentiae are likewise aspects of the essence of forms of those kinds'. ${ }^{29}$

As both Gotthelf and Lennox have pointed out, History of Animals and Parts of Animals contain frequent references to the environment in which an organism performs various activities, such as feeding or cooling, in a way that strongly suggests that performing those activities in that habitat is, in Aristotle's view, simply part of the kind's nature. On the basis of such references, it would appear that Aristotle thinks that it is part of the being or essence of the kind to perform those activities in certain habitats. And if this is, in fact, how Aristotle is thinking about living substances and their habitats, it is no surprise that he never explicitly raises any questions of fit, questions which seemed so pressing to later biologists and philosophers such as Darwin.

${ }^{28}$ A. Gotthelf, 'The Elephant's Nose: Further Reflections on the Axiomatic Structure of Biological Explanation in Aristotle' ['Elephant'], in Kullmann and Föllinger (eds.), Biologie, 85-96 at 9I, repr. in A. Gotthelf, Teleology, First Principles, and Scientific Method in Aristotle's Biology (Oxford, 201 2), I 86-96 at 192.

29 Lennox, 'Bios', 348, and ' $\Pi_{\rho} \hat{\alpha} \xi \iota s ', 252$. 
The general idea that a kind's essence will include its habitat is appealing, but the plausibility of this interpretation of Aristotle depends on how it is developed in detail. One would hope that this general idea could be made precise in a way consistent with Aristotle's other views. In particular, since Aristotle appears to identify an organism's essence with its soul ( $D A$ 2. 4, 4I $\left.5^{\text {b } 8-15}\right)$-its capacities for engaging in vital activities-we need an account of how habitat is related to those capacities comprising soul.

Gotthelf, unfortunately, does not address how the multiple essential features appealed to in explanations are related to one another. His focus is on examining the structure of those explanations, with a view to showing that they do have, at least implicitly, the sort of structure described in the Posterior Analytics. In particular, Gotthelf is interested in presenting evidence that Aristotle's biological writings consider certain features that are appealed to in various explanations to be essential features that would be part of a kind's definition. ${ }^{30}$ Such features are what Gotthelf refers to as the 'givens', features of a kind that explain the presence or character of its other features but that are not 'explained anywhere else in $P A$, and for each of which there is good theoretical or intuitive reason to think that Aristotle considered them explanatorily basic and thus essential to the subject kind' ${ }^{3}{ }^{\text {I }}$ Gotthelf claims that being a marsh animal is among those unexplained explainers of the elephant's trunk, ${ }^{32}$ but does not say how that fact about the elephant is related to its other essential features. ${ }^{33}$ As Gotthelf's concern in

$3^{\circ}$ In Gotthelf's view, in fact, Aristotle in his biology considers many more features than psychic functions to be part of the being or essence of a kind. Gotthelf thinks that in addition to 'standard soul-functions', Aristotle includes in the ov $\sigma$ ía certain body parts, 'dimensional' features such as, perhaps, size and shape of certain limbs, and 'the blend of material elements that constitutes the animal' (A. Gotthelf, 'Notes towards a Study of Substance and Essence in Aristotle's Parts of Animals ii-iv' ['Notes'], in Gotthelf (ed.), Nature, 27-54 at 48, repr. in Gotthelf, Teleology, $2 \mathrm{I} 7-4 \mathrm{O}$ at 238 ). This, as Gotthelf says, puts pressure on 'strongly functionalist interpretations of Aristotelian form' ('Notes', 53-4 n. $22=$ Teleology, 233 n. 27).

${ }^{31}$ Gotthelf, 'Elephant', 86 (=Teleology, I 88). Gotthelf is at times more circumspect about whether references to a kind's ov $\sigma i ́ a$ are to be taken as references to its

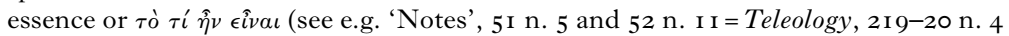
and 223 n. I2.) 32 'Elephant', 87 (= Teleology, I 88).

33 Elsewhere Gotthelf entertains the idea that where an organism eats is not a 'given' but rather is explained by the kind of food it must eat ('First Principles', I 92-3=Teleology, I79). Although eating a sort of food might be a 'given', Aristotle also appears to hold that organisms' food must have 'an elemental blend like their own' (ibid. $193=$ Teleology, $\mathrm{I} 79$ ). This suggests to Gotthelf that 'the blend of material elements makes it causally necessary that an animal feed in a certain place' ('Notes', 
these papers is not to say how but rather only that such features are essential, the idea is not developed in sufficient detail for our purposes.

Lennox's recent work on bios, on the other hand, which can be seen as one way to develop the general idea that essence includes habitat, does say more about the relationship between a kind's habitat and its psychic activities. On Lennox's interpretation, bios is the 'single essential feature of organisms . . . that accounts for the integration of the many physical and functional differences that make different kinds of animals what they are'. ${ }^{34}$ Lennox argues that bios, though not mentioned in works such as the Physics or in the methodological discussions in Aristotle's biological treatises, is given a prominent role in both History of Animals and Parts of Animals. In the former it is one of the four main differentiae around which the data Aristotle presents there are organized. And in Parts of Animals it plays an ineliminable role in explaining why different animals' parts vary in particular ways. Strictly speaking, the character of the body parts is teleologically explained by the functions they are used to perform, but on Lennox's interpretation a kind's bios determines what its vital functions have to be like. That latter role, according to Lennox, is crucial to Aristotle's scientific study of animal parts because Aristotle is acutely aware that explanations of individual parts by reference to individual functions are not sufficient to explain the survival and flourishing of an organism. For the functions too must be co-ordinated or integrated so that they all work together. ${ }^{35} \mathrm{By}$ appealing to bios Aristotle can explain 'why a particular kind of animal has just the set of functions it has' ${ }^{36}$ and so can account for the unity of an animal's many activities and functions: Aristotle conceives of a kind's functions and activities as unified and co-ordinated by its bios. Habitat, on this view, is related to a kind's essential functions

53 n. 20=Teleology, 23 I n. 24). 'Watery' animals, for instance, must feed in water. However, the elemental constitution of a given region is not necessarily the same as a habitat. The fact that something must eat 'watery' food does not entail that it live in a marsh as opposed to, for example, a lake or seashore. For this reason, I do

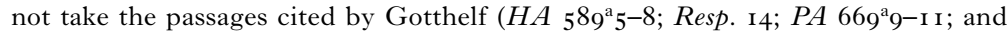
$G C 335^{\text {a }}$ Io) to be clear evidence that a kind's elemental blend explains its having a certain habitat.

34 'Bios', 333.

35 See e.g. Lennox, 'Bios', 350-I, and ' $\Pi \rho \hat{\alpha} \xi \iota s$ ', 254: 'The way of life of an animal demands a coordination of the many "structure/function complexes" that make up the animal. Without that coordination . . . you do not have an organism, i.e. a living unity.'

${ }^{36}$ Lennox, 'Bios', 333, and ' $\Pi \rho \hat{\alpha} \xi \iota s ', ~ 239$. 
by being an aspect of a whole bios that determines what the kind's essential functions have to be like.

Lennox is certainly right to stress the importance, for Aristotle and the modern biologist alike, of accounting not only for the morphological fit of parts to functions but also for the fit between functions. Moreover, scattered remarks that Aristotle makes suggest that he takes himself to be addressing how the parts are co-ordinated with one another, and not merely how the parts are suited for particular functions. There are, however, two reasons that might make one hesitate to accept Lennox's interpretation.

First, it is not clear how this talk of 'integrating' and 'coordinating' is supposed to be made precise, or what it means for activities to be unified 'due to' the bios. Lennox's language ('accounts for', 'explains', 'enforces coordination', 'demands') suggests a causal relation, and in particular the sort of causal and explanatory relation that soul bears to an animal's characteristic behaviours and the functions of its parts. Lennox is clear, however, that he does not think that a kind's bios is equivalent to its soul or essence. And he is clear that he does not think that a kind's essential activities are 'due to' the bios in the sense that they are for the sake of the bios. But since it is neither a formal- nor a final-causal relation, nor presumably an efficient- or material-causal relation, it is not clear how this co-ordinating or integrating role is meant to correspond, if at all, to the quadruple causal framework discussed in the Physics. The nature of the causal and explanatory role that bios plays is, then, somewhat elusive.

Second, as Lennox also notes, there are reasons to wonder how such a complex way of life, with all its many aspects, can be a unitary feature. This is problematic since, according to Lennox, Aristotle's motivation for introducing such a feature as bios was to provide unity to the whole host of functions and activities that comprise a living being's soul or essence. But in order to do this unifying work, the bios must somehow form a unity itself. Given that a kind's bios involves so many different things, it appears that we have just pushed the question back to one about the 'unity of the diverse features of the animal's way of life'. ${ }^{37}$

These obstacles to accepting Lennox's interpretation, though not trivial, are not insurmountable. My interests are more narrowly delimited here, however, and so I would like instead to explore an-

$$
{ }^{37} \text { Lennox, 'П } \hat{a}_{\xi} \iota s \text { ', } 259 .
$$


other option for construing the relationship between habitat and essential psychic activities that could be compatible with, though it does not require, the stronger view advocated by Lennox.

An alternative way to pursue the same general strategy-i.e. the strategy that builds habitat into the essence by assigning it a role in determining what a kind's essential functions and activities must be like-would be to fill in the details as follows. Since a kind's essence is identified with soul, which is a set of capacities for engaging in vital activities, we can think about essences in terms of sets of capacities. Capacities, moreover, can be considered at varying levels of generality. For instance, pastry chefs and barbecue masters both have the general capacity to cook food. However, they each have that capacity in different, more specific ways. One has the pastrychef cooking capacity, the other has the barbecue-master cooking capacity. What determines the precise character of their respective capacities are factors such as where and on what ingredients the capacities are exercised. That is, their capacities are different in virtue of differences in the medium in which their capacities are exercised (oven vs. grill) and differences in the objects upon which they are exercised (flour, butter, sugar vs. meat). Similarly, birds share a general capacity to walk. However, walking in a marsh and walking on rocky cliffs are very different activities. The specific form of walking exhibited by the crane, for example, will differ from that of a falcon in virtue of particular features of the habitat-the marshin which the crane's walking occurs. ${ }^{38}$

Habitat, according to this proposal, gets into the essence by serving as a determinant of the precise way in which organisms have their vital capacities. ${ }^{39}$ Marsh-dweller birds, for instance, are

${ }^{8}$ Just to be clear, the genus-species relationship that obtains between the general capacity to walk and the species of walking exhibited by the marsh-dweller is not to be construed as one that treats 'marsh-dweller' as a differentia of the general capacity. Not every genus-species relationship is one for which there is an independent, extra feature that gets added to the genus to yield a new species. A bird is a specific way of being an animal, but a bird is not animal+some differentia; a bird is a determinate way of being an animal. Just so, being a marsh-dweller bird is not being a bird+some differentia; being a marsh-dweller is a determinate way of being a bird. For a helpful discussion of this contrast between different kinds of genus-species relationships see A. Ford, 'Action and Generality', in A. Ford, J. Hornsby, and F. Stoutland (eds.), Essays on Anscombe's Intention (Cambridge, Mass., 20 I I), 76-104 at 82-90. In Ford's terminology, I take the specific capacities to stand in 'categorial' genus-species relationships to the general ones.

39 An organism's natural habitat cannot, of course, be the only thing serving to determine how the organism has its capacities. There are likely to be several 
not just birds with certain capacities that happen to be exercised best in marshes. Marsh-dweller birds are birds that have those capacities in the marsh-dweller way. That is, 'the marsh-dweller way' is a specification of the way the organism has its vital capacities.

According to this understanding of the relation between essential capacities and habitat, it is natural to read Aristotle's references to organisms' habitats as references to the specific or determinate way they have their vital capacities, such as locomotion. For instance, 'marsh-dweller way of life' is, on my proposal, a reference to the way the bird has its essential vital capacities-in the marsh-dweller way. Consequently, when Aristotle claims that being a marsh-dweller is the cause of some birds having long legs (at $P A 4.12,694^{\mathrm{b}} \mathrm{I} 2$, cited above), he is giving a teleological explanation. It is not that the marsh-dweller birds have long legs for the sake of being in marshes. Rather, they have long legs for the sake of exercising their distinctive capacities, such as their capacity to walk in a certain way. And that Aristotle takes himself to be giving a teleological explanation in this passage is evinced by his commenting in the very next sentence that 'nature makes the instruments to fit the function, not the function to fit the instruments' $\left(694^{\mathrm{b}} \mathrm{I}_{3}-\mathrm{I} 4\right)$. It is for the sake of walking in a certain way-the way a marsh-dweller bird must walk-that those birds have long legs.

\section{5. 'External' conditions and capacities}

In case one is sceptical about including spatially external elements in the essence of a living being, Aristotle's account of perception provides a useful model. $4^{\circ}$ Aristotle thinks that perceptual organs, such as eyes, are defined by the perceptual capacities they are for. And perceptual capacities are essentially defined by reference to their proper external objects. To understand what an eye is, you must know what sight is. To know what sight is, you must know that it is of colour. Similarly, hearing is of sounds, and taste of flavours $\left(D A\right.$ 2. 6, $\left.4 \mathrm{I} 8^{\mathrm{a}} \mathrm{II}-\mathrm{I} 3\right)$. Not only is this an example of Aris-

determinants. Otherwise, all organisms in a certain habitat would have their essential capacities in the same way, which they do not.

${ }^{40}$ I owe thanks to Eve Rabinoff for suggesting perception as a model for the way that something 'external' gets to be 'internal'. 
totle building something spatially external into the specification of a capacity, but his account of perceptual capacities also exemplifies how something external can determine the precise character of a capacity. For the nature of a perceptual capacity's proper object determines what that capacity has to be like, though not by being an efficient cause (as external objects are efficient causes of perceptual episodes). Rather, given that the objects are a certain way, something can be a perceiver only if it has organs with powers that stand in the right relation to the character of those objects. A sighted eye, for instance, has the power or capacity to see, and this power it has, Aristotle says, is a certain ratio. ${ }^{{ }^{\mathrm{I}} \mathrm{T}}$ This is because colour, the per se object of vision, is a certain ratio of light to dark. This explains why plants do not perceive: they do not have a mean (mesotess)—the proper ratio-and so cannot be receptive of the form of a sensible object (e.g. the form of a colour, which is a certain ratio) without the matter. So there is a quite clear sense in which the capacity to see is what it is in virtue of its objects being what they are. ${ }^{42}$

Aristotle's account of perception, then, shows us how the object of a capacity determines what the capacity is like. In addition, it exemplifies how the context in which a capacity is exercised does so as well. For there is a further feature of Aristotle's account of perception that is relevant to this discussion, namely, the medium in which perceptual capacities are exercised. Vision, hearing, and smell are, essentially, capacities for doing certain things or being affected in certain ways under certain conditions, e.g. in a transparent medium. And the ways that organisms have their perceptual capacities will be different in different media. For example, some animals smell in water and some smell in air. Both water-dwellers and landdwellers have the same capacity to smell, Aristotle says, but they smell in different media and so have it in different ways. ${ }^{43}$ One does so by breathing, which is analogous to opening one's eyelids, and the other perceives smell in the watery medium directly. The medium is not merely the 'enabling' condition for the exercise of an organism's perceptual capacities: the character of the medium affects

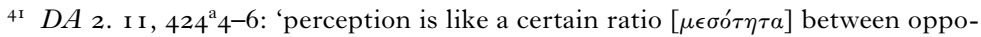
sites among the perceptibles. And on account of this it discerns the perceptibles. For

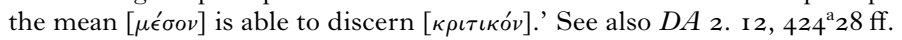

${ }^{2}$ Thanks to Joel Yurdin for helpful discussions about this.

43 See De sensu $5,444^{\mathrm{b}} 20-8$. Since both kinds of organisms perceive odours-the per se objects of smell-they both have this perceptive power, 'but perhaps not in

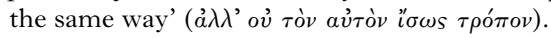


the nature of the capacity. Analogously, on my account, habitats are not merely external or enabling conditions under which organisms exercise vital capacities: the character of the habitat is built into the specification of the particular way the kind has its vital capacities. ${ }^{44}$

\section{Natural changes}

The way that Aristotle's account of perception builds spatially external features into the specification of the capacities is helpful, I have suggested, in showing the plausibility of the interpretation I am offering. As is the case with perception, specifying what any other vital capacity is must include spatially external factors, such as habitat. As I will now discuss, the analogy with perception is also helpful in shedding important light on certain philosophical and methodological assumptions in Aristotle's scientific practices.

It follows from the way I have been suggesting that Aristotle conceives of the relationship between an organism's habitat and its essence that the nature of a living organism, and the changes that are due to that nature, cannot be understood in abstraction from the context in which it essentially belongs. Just as one can make sense of the changes and activities that constitute the life of an organism only when understood in the context of an entire life cycle, and not when viewed at a single moment in time, those changes and activities will make sense only when considered in the light of the conditions that are essentially implicated in them. Living substances are what they are partially in virtue of the spatially external factors that living substances have the capacities on which to act and by which to be affected. Consequently, in so far as natural science aims to understand those changes and activities that constitute the lives of

${ }_{44}$ This is not the place to embark on a full discussion of Aristotle's comments in Metaphysics $\Theta 5$, but scholars have taken him to be asserting there something like the view that enabling conditions are not external to but definitive of the capacity they enable. It is identified as the 'more interesting reading' of two ways of understanding I $047^{\mathrm{b}} 35^{-10} 48^{\mathrm{a}} 2$, discussed by S. Makin, Aristotle: Metaphysics Book Theta (Oxford, 2006), Iо3 ff. Similarly, J. Moline states that Aristotle "conceives of the force of a true capacity claim as being narrowly circumscribed by the circumstances under which the capacity in question is in fact manifested. He thinks of what some would call "external interferences" not as limitations upon the exercise of a capacity which one possesses in any case; rather he conceives of them as circumscribing and defining more narrowly the capacity itself, as refuting inexact conceptions of the capacity in question' (J. Moline, 'Provided Nothing External Interferes', Mind, 84 ( I 975), 24454 at 249). See also T. Johansen, The Powers of Aristotle's Soul (Oxford, 20 I 2), 75-8. 
living organisms, it is the business of a natural scientist to study living organisms in their natural habitats.

The requirement that living organisms be studied in their natural habitats has far-reaching implications for our assessment of Aristotle's practices in his natural science. It has been alleged to be a weakness of Aristotle's natural science that it does not consider the changes an organism might undergo when removed from its habitat-including changes in its behaviour-to be ones that exhibit its nature or essence. Solely what an organism does in its natural setting is thought to manifest its essence. His view has been contrasted unfavourably with our current belief that an organism's changes in all types of circumstances, not merely its usual or typical ones, are 'equally natural to it'. ${ }^{45}$ Waterlow has criticized Aristotle's exclusive focus on what an organism does in its natural habitat as follows:

What more understandable for a virtual pioneer in natural philosophy than to assume that the natures of things can be read off from such changes alone, and to consign all other reactions to the category of the 'incidental', as reflecting nothing intrinsic in the objects that suffer them, but only the tendency of an interfering force? . . But a notion with plausible illustrations is not necessarily a coherent concept capable of actual instantiation, and we may well doubt the sense, as well as the scientific usefulness, of a view which obliges us to identify the changes natural to a given object with a mere sub-class of those occurring in it through perfectly natural causes. ${ }^{46}$

As Waterlow sees it, Aristotle's failure to consider the changes that take place in non-typical circumstances as natural is an unfortunate consequence of his metaphysical views about natural substances. Natural substances differ from artefacts in that they have natures'inner principles of change and rest'-and so can be the sources of their own changes. This implies that although external factors might play a role in determining whether or not some change occurs in an organism, they have no part to play in shaping the character of the change, according to Waterlow. This leads Aristotle to ignore the influence that non-typical conditions exert on an organism's changes, Waterlow claims, since those conditions would have no bearing on the kinds of changes of which an organism's nature can be the source. If he were to allow external conditions to shape or determine organisms' natural changes, according to Wa-

\footnotetext{
45 Waterlow, Nature, $35 . \quad 4^{6}$ Waterlow, Nature, 30.
} 
terlow's diagnosis, it would threaten their status as causally autonomous substances with internal principles of change:

If the nature of a natural substance is exhibited in the changes whose character it autonomously determines, then in these changes the only role left to the external conditions is that of permitting the change or not hindering it. It follows that if the conditions do hinder it, the resulting situation, whether it is a new change or quiescent state, does not exhibit the substantial nature. ${ }^{47}$

And this conclusion-that changes in different conditions do not exhibit a kind's nature-is a mistake, according to Waterlow. ${ }^{48}$ For, as she points out, surely the changes an organism undergoes in all sorts of circumstances are equally changes that are natural for it.

I agree that Aristotle thinks the changes an organism undergoes outside of its natural habitat do not exhibit its essential nature. But I disagree about the relationship natural habitat stands in to essence, and so disagree that this is a mistake for Aristotle. I think that Aristotle is viewing habitats as partially constitutive of essential capacities, rather than merely the background conditions that might permit or hinder their exercise. Accordingly, since it is part of the essence of a kind to dwell in certain habitats, the idea that its changes in alternative circumstances do not exhibit its nature is not a naïve mistake, but rather a substantive thesis.

If I am correct, Aristotle has every reason to think that what organisms do in their habitats constitutes changes that reveal their essences, and what they do in other situations does not. Attending once again to the parallels with perception helps us to see why this is so. For an organism's capacities are related to its natural habitat in the way that a sighted eye's power to see is related to the transparent medium in which it exercises that power. The changes that an eye undergoes in the absence of a transparent medium are, surely, changes that are possible for it. However, not every change that it is possible for something to undergo is one for which it has an essential capacity, and only those changes which are the exercises of essential capacities can reveal its essence. ${ }^{49}$ Given that Aristotle thinks vision

47 Waterlow, Nature, 29.

$4^{8}$ Waterlow, Nature, 34: 'But it is surely a crude mistake to think that an object's unitary nature is manifested only in behaviour of a single observable pattern.'

49 This line of thought is in the spirit of suggestions made by A. D. P. Mourelatos, 'Aristotelian Powers and Modern Empiricism', Ratio, 9 ( 1967), 97-104, about Aristotle's conception of capacities that are constitutive of a $\phi \dot{v} \sigma \iota s$. 
essentially takes place in a transparent medium, a sighted eye in the dark is not performing its essential function. Since an eye in the dark is not doing what it is of the essence of an eye to do, whatever it does is not revealing anything about its essential nature or function. And it is the eye's essential nature or function that Aristotle, in trying to understand the natural world, is concerned to understand.

Similarly, an organism outside of its natural habitat will undergo various changes and may very well survive, but it is not living the life distinctive of its kind. Those things that it can do in alternative habitats are not, for Aristotle, capacities constitutive of its essential nature, any more than what an eye can do in the dark is among the eye's essential capacities. An eye in the dark is not exercising some other capacity that it has; it is trying, and failing, to exercise its perceptual capacity. So too, a fish flopping on the shore is not exercising some other locomotive capacity; it is trying, and failing, to exercise its capacity to swim.

Just to be clear, knowing what an eye does in the dark can be useful in an investigation of eyes, of course. And it is certainly the case that Aristotle thinks that what we observe organisms doing outside of their habitats is relevant to scientific enquiry. For instance, the fact that fish choke out of water (as Aristotle reports) is useful in a scientific investigation into their distinctive way of cooling themselves (with water, through gills). This bit of data is, in fact, employed by Aristotle to refute the view that fish respire by drawing air from the surrounding water (Resp. $3,47 \mathrm{I}^{\mathrm{b}} \mathrm{I} 2 \mathrm{ff}$.). Although it is relevant for a natural scientist to know that a fish chokes out of water, a fish has no essential capacity to do this. Choking out of water does not reveal the fish's essence or exhibit its nature.

Thinking that how a creature behaves in other habitats does not reveal its essence is a mistake only if one thinks of habitats as simply background conditions that permit or hinder a kind's essence to be realized. If instead, as I have argued, it can be essential to natural substances that they perform their vital activities in certain habitats, trying to learn about the nature of those organisms by seeing what they do outside of their habitats would be like trying to learn about an eye in pitch darkness.

Thus Aristotle's refusal to consider what organisms do in nonnatural settings as changes that reveal their essences, if the proposal argued for here is correct, is justified. A human living outside of a polis is either 'worse or greater than human' (Pol. I. 2, 1253 ${ }^{\mathrm{a}} 2-4$ ), 
and it is a human life that Aristotle cares about understanding. A flourishing human life, Aristotle thinks, essentially involves living in a certain sort of habitat. The same goes for other living beings.

\section{Conclusion}

I began by observing that Aristotle is aware of the advantageous fits between organisms and their natural habitats. It would be surprising if he thought this to be coincidental, given how vehemently he insists that beneficial arrangements of parts within organisms cannot be merely lucky coincidences. And it would not only be surprising: it runs counter to the way Aristotle talks about beneficial correlations between organisms and where they dwell. For instance, he says that 'residents by seas and rivers and lakes include all the web-footed; for nature itself seeks what is suitable' ( $H A 8$ (9). I 2 , 6 I $\left.5^{\mathrm{a}} 24-6\right)$.

This comment indicates that for Aristotle it is 'nature itself' that ensures the fit between web-footed creatures and living near water. But this is ambiguous. It is possible to read this as claiming that, as a view such as Sedley's would have it, a global nature is responsible for the fit. And it is also possible to read this as claiming that the individual natures of the sea, river, and lake residents are responsible, perhaps because they can respond to their environments by forming webbed feet. But neither of these readings is attractive. As I argued, in order to make an appeal to global teleology provide a satisfying answer, the view that there is a cosmic nature must be attributed to Aristotle, which is controversial. And an attempt at an answer running from environmental factors to the organisms' parts can be successful only if the environment can cause changes to the essential functions those parts are needed to perform. Yet that requires some notion of adaptation over time, which appears to conflict with Aristotle's view that kinds are fixed and eternal.

What I proposed instead is that Aristotle considers a kind's natural habitat to be built into the character of its essential capacities. As I read that remark in History of Animals, he is claiming that the natures of those sea-, river-, and lake-dwellers are responsible for their useful webbed feet, just in the way that the natures of humans are responsible for humans having the arrangement of teeth that we do. So, I think we should not hear comments about the habitat in 
which an organism lives as references merely to the 'arena' in which an animal exercises its capacities, but rather as elliptical references to those vital capacities that are constitutive of their being the kinds of organisms that they are.

If we take on board this suggestion about how to conceive of an organism's habitat in relation to its vital capacities, the answer to questions of fit is obvious and trivial. For now the form of our question is not 'Why are birds that have these parts and natural capacities so well suited to living in marshes?', but rather 'Why are birds that have their natural capacities in the marsh-dweller way so well suited to living in marshes?'. And asking that latter sort of question is like asking why swimmers are so well suited to moving in water, or why it is colour that vision perceives. As questions about how the parts of a swimmer's body fit together, or about the structure of the eye, these are perfectly fine questions, and ones for which Aristotle has answers. But if these are questions about the fit between a certain sort of movement (swimming) and where it is exercised, or about why perception is of perceptibles, I think we would not ask them. So, if I am right that Aristotle thinks an organism's habitat is built into its essence, this is exactly how he would hear questions of fit, and thus it is unsurprising that he never raises them..$^{\circ}$ For those are questions that Aristotle would have considered absurd, just as he thought it absurd to ask 'why the curable, when moved and changed $q u a$ curable, progresses towards health and not towards whiteness' or 'why fire is carried upwards and earth downwards' (De caelo 4. 3, $310^{\mathrm{b}}$ I 6 ff.).

University of Pittsburgh

\section{B I B L IOGRAPHY}

Balme, D. M., Aristotle: De partibus animalium I and De generatione animalium I (with Passages from II. I-3). Translated with Notes, with a Report on Recent Work and an Additional Bibliography [De partibus] (Oxford, I 992).

$5^{\circ}$ I. Bodnár makes a similar suggestion about why we do not find Aristotle trying to explain interspecies teleological relationships in his biological works. Bodnár claims that the description of the ways of life and characteristic activities of biological organisms 'will also set out those elements of their habitat which contribute to the well-being of these animals. Accordingly, the description of biological natures already contains the way the animal, in a teleological manner, meshes in with its environment' (Bodnár, 'Teleology', 27). 
Balme, D. M., 'Aristotle's Use of Division and Differentiae', in Gotthelf and Lennox (eds.), Issues, 69-89.

Bodnár, I., 'Teleology across Natures' ['Teleology'], Rhizai, 2 (2005), 9-29.

Code, A., 'The Priority of Final Causes over Efficient Causes in Aristotle's $P A$ ', in Kullmann and Föllinger (eds.), Biologie, I 27-43.

Cooper, J., 'Aristotle on Natural Teleology', in M. Nussbaum and M. Schofield (eds.), Language and Logos: Studies in Ancient Greek Philosophy Presented to G. E. L. Owen (Cambridge, 1982), 197-222.

Ford, A., 'Action and Generality', in A. Ford, J. Hornsby, and F. Stoutland (eds.), Essays on Anscombe's Intention (Cambridge, Mass., 20 I I), 76-ro4.

Gotthelf, A. (ed.), Aristotle on Nature and Living Things [Nature] (Pittsburgh, I 985 ).

Gotthelf, A., 'First Principles in Aristotle's Parts of Animals' ['First Principles'], in Gotthelf and Lennox (eds.), Issues, г 67-98; repr. in Gotthelf, Teleology, I 53-85.

Gotthelf, A., 'Notes towards a Study of Substance and Essence in Aristotle's Parts of Animals ii-iv' ['Notes'], in Gotthelf (ed.), Nature, 27-54; repr. in Gotthelf, Teleology, 21 7-40.

Gotthelf, A., Teleology, First Principles, and Scientific Method in Aristotle's Biology [Teleology] (Oxford, 2012).

Gotthelf, A., 'The Elephant's Nose: Further Reflections on the Axiomatic Structure of Biological Explanation in Aristotle' ['Elephant'], in Kullmann and Föllinger (eds.), Biologie, 85-96; repr. in Gotthelf, Teleology, I 86-96.

Gotthelf, A., and Lennox, J. G. (eds.), Philosophical Issues in Aristotle's Biology [Issues] (Cambridge, i 987 ).

Johansen, T., The Powers of Aristotle's Soul (Oxford, 201 2).

Judson, L., 'Aristotelian Teleology' ['Aristotelian'], Oxford Studies in Ancient Philosophy, 29 (2005), 341-66.

Kahn, C., 'The Place of the Prime Mover in Aristotle's Teleology', in Gotthelf (ed.), Nature, I 83-205.

Kullmann, W., and Föllinger, S. (eds.), Aristotelische Biologie: Intentionen, Methoden, Ergebnisse [Biologie] (Stuttgart, I 997).

Lamarck, J. B., Zoological Philosophy: An Exposition with regard to the Natural History of Animals, translated, with an introduction by Hugh Elliot (London, I9I4).

Lennox, J. G., Aristotle: On the Parts of Animals I-IV. Translated with an Introduction and Commentary [Parts] (Oxford, 2001).

Lennox, J. G., Aristotle's Philosophy of Biology: Studies in the Origins of Life Science [Biology] (Cambridge, 200 I). 
Lennox, J. G., 'Bios and Explanatory Unity in Aristotle's Biology' ['Bios'], in D. Charles (ed.), Definition in Greek Philosophy (Oxford, 2010), 329-55.

Lennox, J. G., 'Bíos, $\Pi_{\rho} \hat{\alpha} \xi \iota s$, and the Unity of Life' [' $\Pi_{\rho} \hat{\alpha} \xi \iota s$ '], in S. Föllinger (ed.), Was ist 'Leben'? Aristoteles' Anschauungen zur Entstehung und Funktionsweise von Leben. Akten der Tagung vom 23.-26. August 2006 in Bamberg (Stuttgart, 2010), 239-59.

Lennox, J. G., 'Divide and Explain: The Posterior Analytics in Practice', in Gotthelf and Lennox (eds.), Issues, 90-I I 9; repr. in Lennox, Biology, $7-38$.

Lennox, J. G., 'Kinds, Forms of Kinds, and the More and the Less in Aristotle's Biology', in Gotthelf and Lennox (eds.), Issues, 339-59; repr. in Lennox, Biology, i6o-8 г .

Leunissen, M., 'Aristotle on Natural Character and its Implications for Moral Development' ['Character'], Fournal of the History of Philosophy, $5 \circ$ (2012), 507-30.

Leunissen, M., Explanation and Teleology in Aristotle's Science of Nature [Explanation] (Cambridge, 2010).

Makin, S., Aristotle: Metaphysics Book Theta (Oxford, 2006).

Moline, J., 'Provided Nothing External Interferes', Mind, 84 (1975), 244-54.

Mourelatos, A. D. P., 'Aristotelian Powers and Modern Empiricism', $R a$ tio, 9 ( 1967 ), 97-104.

Sedley, D., Creationism and its Critics in Antiquity [Creationism] (Berkeley, 2007).

Sedley, D., 'Is Aristotle's Teleology Anthropocentric?' ['Anthropocentric'], Phronesis, 36 (I991), I 79-96.

Sedley, D., 'Metaphysics A', in D. Charles and M. Frede (eds.), Aristotle's Metaphysics 1: Proceedings of the Fourteenth Symposium Aristotelicum (Oxford, 2000), 327-50.

Sedley, D., 'Teleology, Aristotelian and Platonic', in J. G. Lennox and R. Bolton (eds.), Being, Nature, and Life in Aristotle: Essays in Honor of Allan Gotthelf (Cambridge, 2010), 5-29.

Wardy, R., 'Aristotelian Rainfall or the Lore of Averages' ['Rainfall'], Phronesis, 38 (I 993), I 8-30.

Waterlow, S., Nature, Change, and Agency in Aristotle's Physics [Nature] (Oxford, 1982). 